\title{
Overlapping Zone Partitioning Localisation TECHNIQUE FOR RFID
}

\author{
Kavi K. Khedo ${ }^{1}$, Dassen Sathan ${ }^{2}$, Roushdat Elaheebocus ${ }^{3}$, Raja K. Subramanian ${ }^{4}$ and \\ Soonil D.D.V. Rughooputh ${ }^{5}$ \\ ${ }^{1,2,3,4}$ Department of Computer Science and Engineering, Faculty of Engineering, University \\ of Mauritius \\ ${ }^{1} \mathrm{k} \cdot \mathrm{khedo@uom} \cdot \mathrm{ac} \cdot \mathrm{mu}$ \\ ${ }^{2}$ d.sathan@uom.ac.mu \\ ${ }^{3}$ roushdat@gmail.com \\ ${ }^{4}$ rks@uom.ac.mu \\ ${ }^{5}$ Department of Physics, Faculty of Science, University of Mauritius \\ ${ }^{5}$ sdr@uom.ac.mu
}

\begin{abstract}
Basically used for contactless identification, Radio Frequency Identification (RFID) technology was originally thought as a complement for the drawbacks of the Barcode. Due to its capabilities and on-going drop in cost, researchers have started to look into other areas where RFID can be employed. One such area of research is Real-Time Location Tracking (RTLT), especially for indoor environments. While technologies such as UltraSound, Infrared, WiFi, Bluetooth and GSM have been considered for indoor localisation, their requirements for line of sight and/or prohibitive cost have hindered their successful adoption. We are therefore presenting a lowcost solution using RFID technology which we refer to as the 'Overlapping Zone Partitioning' (OZP) technique that can be implemented using basic off-the-shelf RFID Readers and which has been derived from the zonebased localisation technique. We have successfully implemented OZP and evaluated its performance. It has been found that its accuracy is enhanced by nearly $40 \%$ in comparison to a normal zone-based localisation system. Its performance in terms of correct zone classification is within the range of $80-90 \%$.
\end{abstract}

\section{KEYWORDS}

RFID, Zone-Based Localisation, Overlapping Zone Partitioning (OZP)

\section{INTRODUCTION}

Radio Frequency Identification (RFID) can be understood as a technology primarily used to identify 'things' by emitting radio waves and interpreting the responses received. A basic RFID system consists of at least one reader and tags, also known as transponders. There exist two main (although hybrids exist) type of tags [2]: (i) Active tags, having their own power-source in the form of batteries and usually offering longer detection ranges. (ii) Passive tags, on the other hand, rely on the power transferred wirelessly from readers to respond. This implies a much shorter range but virtually unlimited lifetime.

One of the earliest uses of RFID was during WWII [1] whereby radio signals were used to distinguish friendly planes from that of enemies and is known as the Identification Friend or Foe (IFF). Since 
then, RFID has been employed in a large variety of applications such as Security [1, 3], Supply Chain Management [4, 5], Healthcare [6, 7], Luggage Management at airports [8] and many others.

Real-Time Location Tracking [RTLT] is another area which has interested researchers of RFID [9]. While GPS is well-known for its localisation capability in outdoor environments, signals from satellites can hardly penetrate into buildings thus making it useless for indoor localisation. Using short-range signals such Ultra-Sound [10] and Infrared [11] is effective only when there is line of sight and the presence of obstacles hinders performance. WIFI [12], Bluetooth [13] and GSM [14] on the other hand involve a high investment cost for the equipment needed. Since RFID technology has no requirement for line of sight and its cost is going down, it is seen as good candidate for indoor localisation.

Several techniques proposed for using RFID in localisation have been reviewed. Most of them are costly and require specialised RFID Readers and/or a great number of readers for the systems to function. Based on our earlier paper [15], we have found that the Overlapping Zone Partitioning (OZP) technique can theoretically overcome the need for specialised readers and significantly cutdown cost. OZP is an enhancement of the basic zone-based localisation technique. We have designed and implemented OZP to confirm our expectations published in [15] in a real-life scenario.

This paper is organised as follows: A brief introduction to the RFID technology was given as well as the current drawbacks of indoor localisation techniques and we have proposed OZP as a solution in this section. Section 2 explores the related works performed in the area of localisation making use of RFID. Section 3 explains the rationale behind OZP and its design. The implementation is presented in section 4, while the results obtained from OZP are presented and discussed in section 5. We conclude in section 6 with a reflection about OZP and future works.

\section{RELATED WORKS}

Previous works on localisation using RFID have focussed on the use of metrics such as time, angle and signal strength $[15,16,17]$. Algorithms making use of one or a combination of these metrics can then compute the location of an RFID tag. The main algorithms are described briefly below.

\subsection{Multilateration}

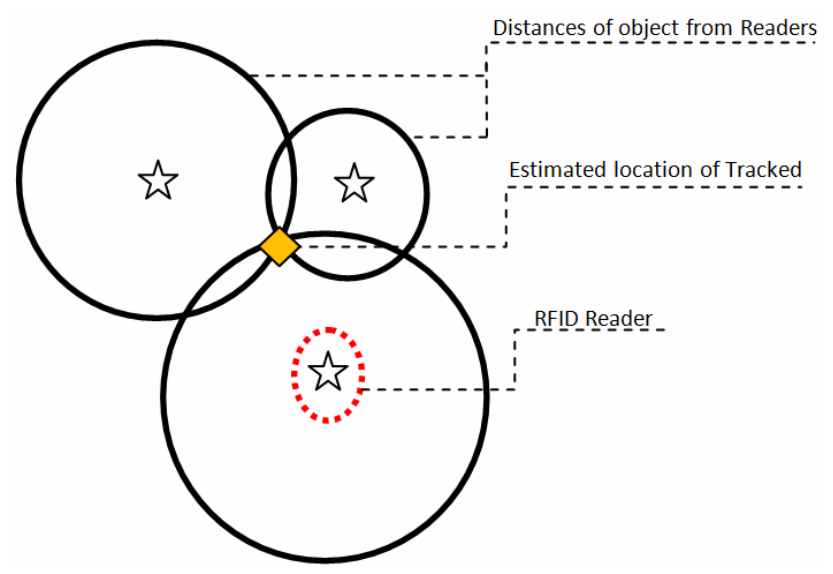

Figure 1. Localisation using trilateration

Often confused with triangulation, multilateration is about deriving the coordinates of a tag by finding the intersection points of three or more readers' distances from the tag. The minimum number of readers required is three, in which case it is referred to as trilateration, shown in Figure 1. By using more readers, thus the term 'multilateration', accuracy can be further enhanced. This has been one of the most popular localisation algorithms used by researchers. [18-20] 


\subsection{Bayesian inference}

Making use of probability and recursion on a set of data collected through an appropriate metric, particularly signal strength, coordinates of a tag can be obtained. Bayesian inference-based algorithms are often used to track mobile objects. [21-23]

\subsection{Nearest-neighbour}

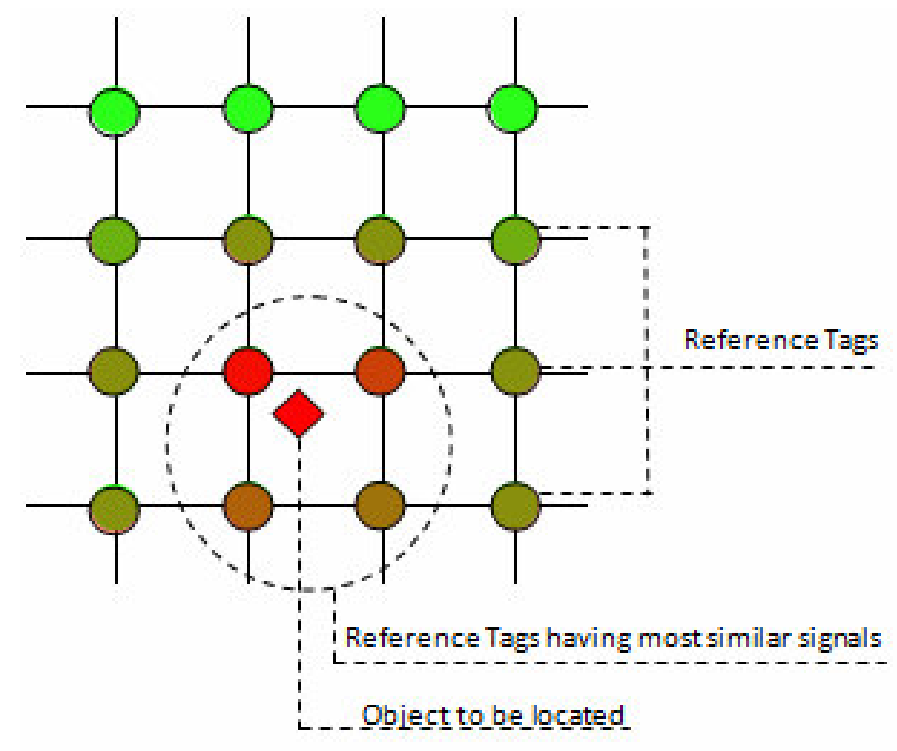

Figure 2. Using reference tags with known location to compare signal strength similarity

By placing reference tags in a grid layout as in figure 2, tagged objects can be located by comparing their signal strengths with that of the reference tags. Since the location of those reference tags are known beforehand, those with the greatest similarity with the tracked object are used as location estimate. It has been used in LANDMARC [24] and several other systems such as CN-TOAG [25] which tries to optimise the nearest-neighbour reference tag comparison process.

\subsection{Proximity}

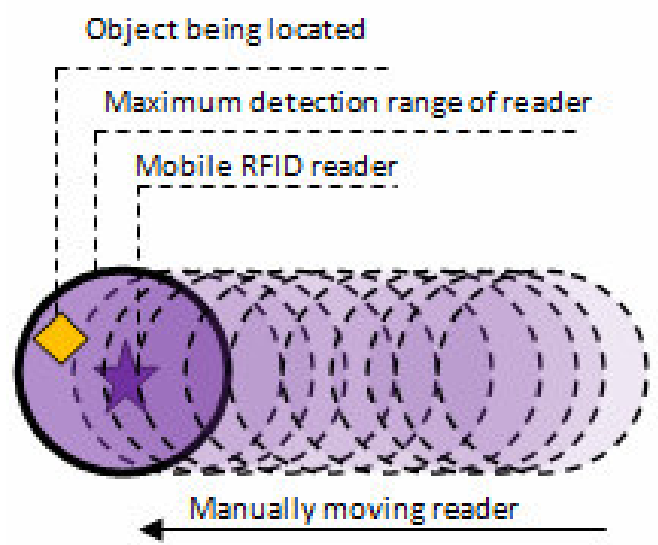

Figure 3. Proximity localisation using a mobile RFID Reader 
Using mobile readers with small coverage areas, tracked objects' locations can be determined by moving around and figuring when tags can be detected. This has been depicted in figure 3 for instance, He, T. et al [26] used it for localisation in a wireless sensor network while Song, J. et al [27] used it to locate materials on construction sites. [28]

\subsection{Kernel-based learning}

A bit similar to the proximity-based algorithm, the Kernel-based learning method is a more generalised one due to the fact that coverage areas overlap in arbitrary shapes. A sample of training data, consisting of radio signal readings transmitted from a number of access points and received at a training point along with that of their physical distances in the form of a vector is fed into the algorithm which learns its parameters based on it [29, 30].

Most of the research work assumed that RFID readers used for implementing those algorithms are capable of providing at least one metric. However, such is not the case for the majority of RFID readers available on the market. Thus, coming up with a localisation technique that can be implemented with low-cost and readily available readers will benefit potential stakeholders in the short-term while the cost for more advance readers remains high. This warrants our OZP localisation technique presented in the next section.

\section{DESIGN OF OVERLAPPING ZoNe PARTITIONING (OZP)}

OZP's design is based on our previous work [15] for the development of a zone-based localisation technique. For a first instance, we have used a 50 metres corridor in the Computer Science Department Building at the University of Mauritius as testing area having some mobile obstacles in the form of staff and students.

OZP makes use of active RFID tags thus having longer detection range, three RFID readers with omni-directional antennas for covering the different zones and two RFID readers with plate antennas for tracking entrance/exit points.

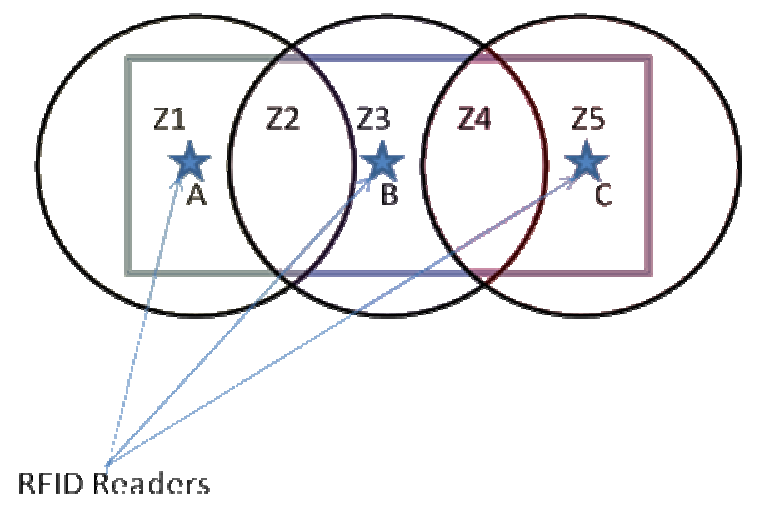

Figure 4. Overlapping of Coverage Areas

Using a normal zone-based approach, only three zones of larger areas would have been obtained. By overlapping the coverage areas and using the intersecting areas, that is, where the reading ranges of two readers overlap, we obtain two more zones as shown in figure 4. The five zones are defined as follows:

- $\mathrm{Z} 1=\mathrm{A}+\mathrm{B}^{\prime}+\mathrm{C}^{\prime}$

- $\mathrm{Z} 2=\mathrm{A}+\mathrm{B}+\mathrm{C}^{\prime}$

- $\mathrm{Z} 3=\mathrm{A}^{\prime}+\mathrm{B}+\mathrm{C}^{\prime}$

- $\mathrm{Z} 4=\mathrm{A}^{\prime}+\mathrm{B}+\mathrm{C}$

- $\mathrm{Z} 5=\mathrm{A}^{\prime}+\mathrm{B}^{\prime}+\mathrm{C}$ 
Whereby A, B and C are RFID Readers and Z1-Z5 are the five zones.

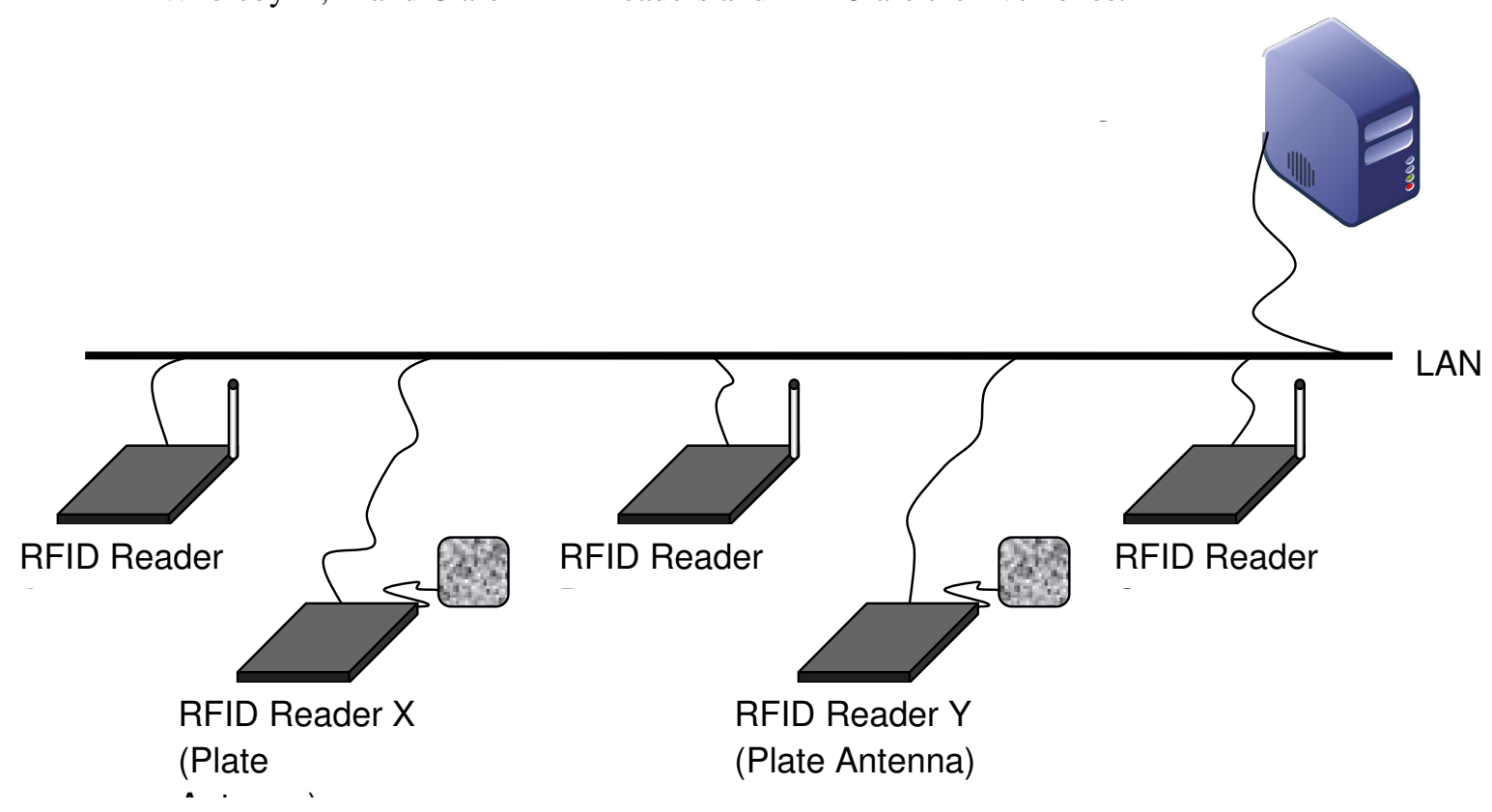

Figure 5. OZP's Hardware Deployment

The RFID readers are connected to a Local Area Network (LAN) along with the Server as shown in figure 5. In our case, the existing LAN infrastructure on the university campus has been used and each reader has been manually configured with an IP address along with the IP address of the server. Reader A, B, and C are placed along the corridor while Reader $\mathrm{X}$ and $\mathrm{Y}$ are located at the exit/entrance points.

\section{IMPLEMENTATION}

\subsection{Hardware Configuration}

In order to implement OZP, some parameters such as the gain configuration for each reader and the distance to leave in between every two readers had to be determined. Thus, we proceeded with some data gathering using the demo-software that came with the RFID readers' SDK.

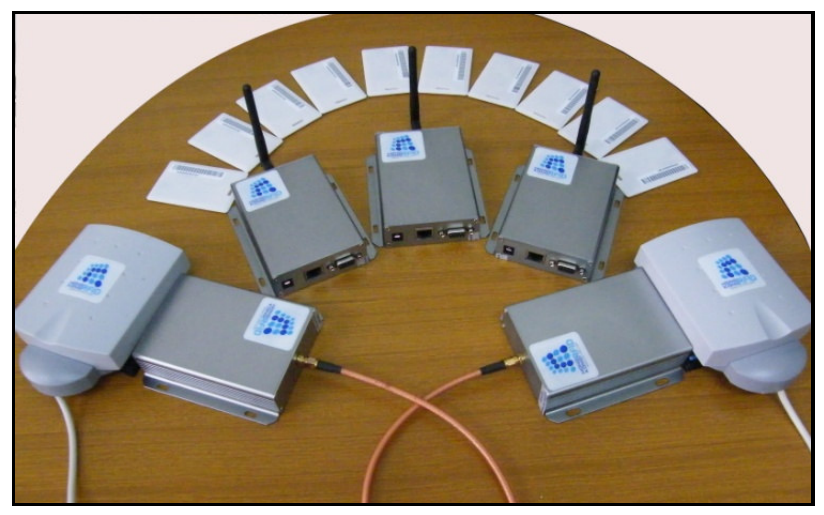

Figure 6. RFID Equipment used (RFID tags and readers)

Using ten sample tags (shown in figure 6), we have collected data on what percentage of these tags are detected at different distances with varying gain values. The graph below was then generated based on the data. 


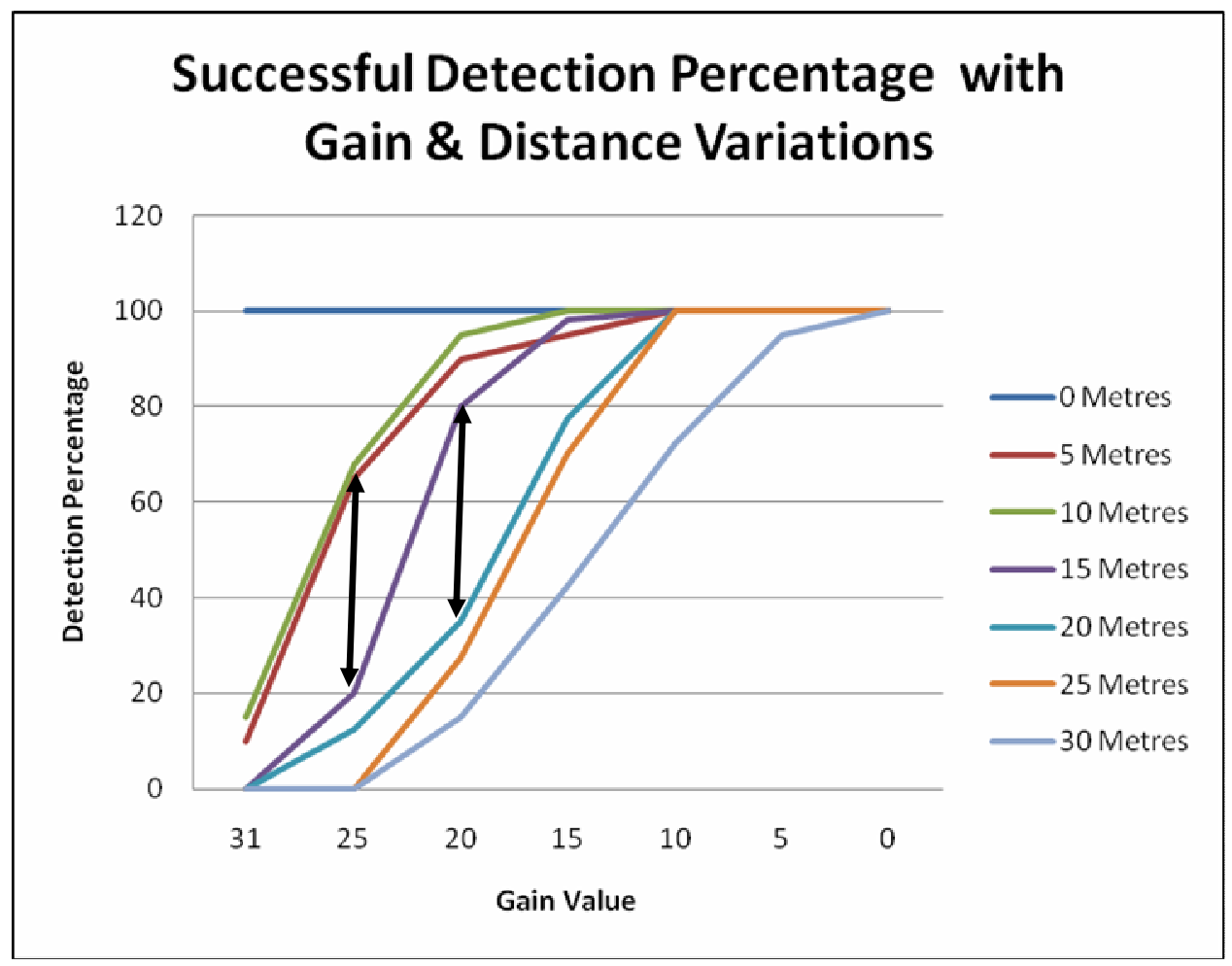

Figure 7. Successful Detection Percentage

Our readers' gain-value can be configured with values between 0-31 inclusive, with 0 offering the largest coverage area. The graph in figure 7 is crucial for determining the most appropriate gain value and placement of the readers. Based on the graph, we have seen a significant drop in percentage of tag detection between the $5 \mathrm{~m} \& 15 \mathrm{~m}$ distances at a gain of 25 and $15 \mathrm{~m} \& 20 \mathrm{~m}$ distances at a gain of 20 (indicated by the vertical double-arrow lines). We have chosen to use the second drop, $15 \mathrm{~m} \& 20 \mathrm{~m}$, since this will allow a larger area to be covered by the system.

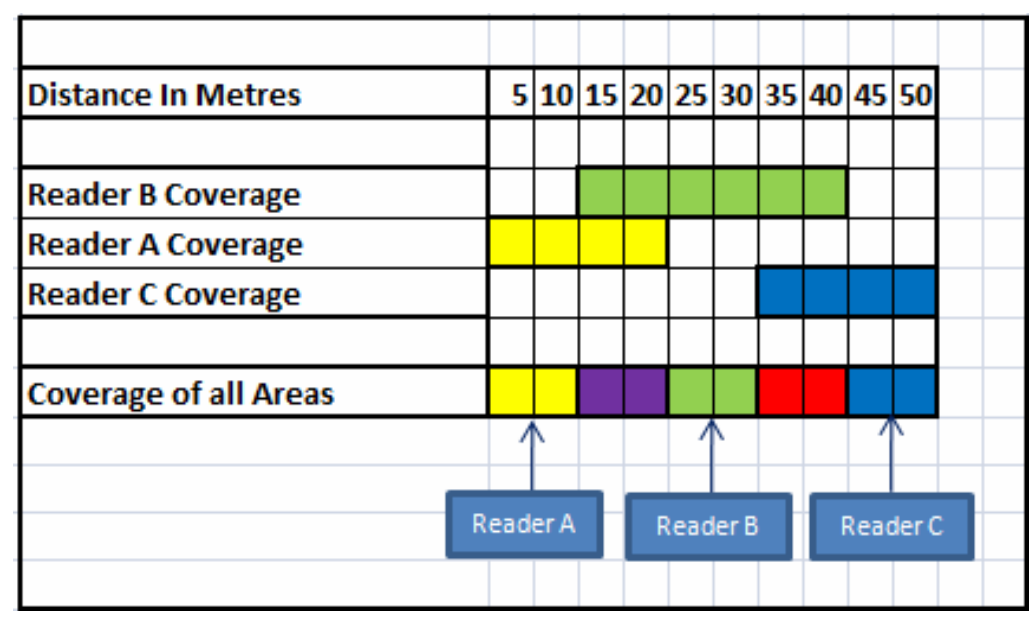

\begin{tabular}{|l|l}
\hline Zone 1 & \\
\hline Zone 3 & \\
\hline Zone 3 & \\
\hline Zone 4 & \\
\hline Zone 5 & \\
\hline
\end{tabular}

Figure 8. Distance Coverage and Readers' Location

The readers' location and their distance from one another is shown in Figure 8, along with the different zones depicted by different colours. The placements of the readers A, B \& C are indicated by the three red arrows in Figure 9. While readers X \& Y (with plate antennas) have been deployed at entrance/exit points as shown in figure 10. 


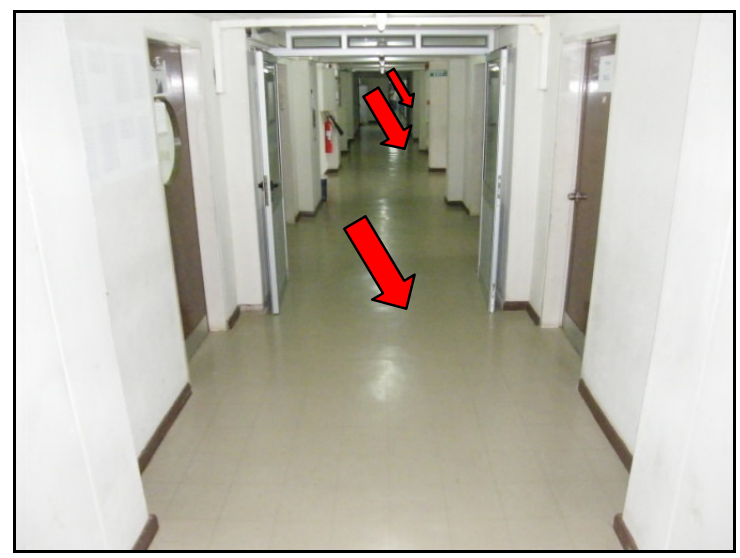

Figure 9. Readers' placements across the test-area

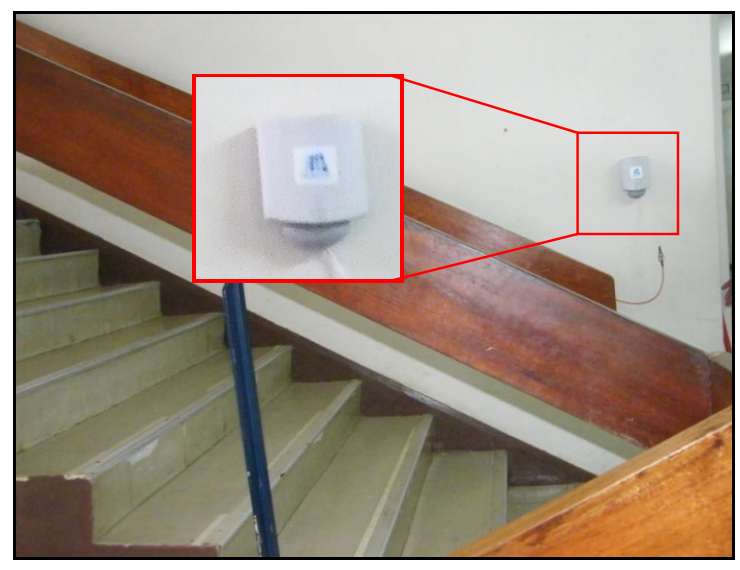

Figure 10. Plate Antenna placed at an entrance/exit point

Table 1. Time difference between each reading

\begin{tabular}{|l|r|r|r|}
\hline $\begin{array}{l}\text { Reading/ Time } \\
\text { Difference(Ms) }\end{array}$ & $\begin{array}{l}\text { Reader } \\
\text { A }\end{array}$ & $\begin{array}{l}\text { Reader } \\
\text { B }\end{array}$ & \multicolumn{1}{l|}{$\begin{array}{l}\text { Reader } \\
\text { C }\end{array}$} \\
\hline $\mathbf{1}^{\text {st }}$ & 5430 & 7016 & 4029 \\
\hline $\mathbf{2}^{\text {nd }}$ & 2543 & 2541 & 2437 \\
\hline $\mathbf{3}^{\text {rd }}$ & 2450 & 3244 & 1640 \\
\hline $\mathbf{4}^{\text {th }}$ & 2409 & 1615 & 3229 \\
\hline $\mathbf{5}^{\text {th }}$ & 2408 & 1610 & 2417 \\
\hline $\mathbf{6}^{\text {th }}$ & 2433 & 2409 & 2441 \\
\hline $\mathbf{7}^{\text {th }}$ & 2408 & 1615 & 2413 \\
\hline $\mathbf{8}^{\text {th }}$ & 2408 & 2409 & 2415 \\
\hline $\mathbf{9}^{\text {th }}$ & 2461 & 2465 & 2411 \\
\hline $\mathbf{1 0}^{\text {th }}$ & 2815.8 & 2816 & 2585.4 \\
\hline Average time difference & 2545.333 & 2396 & 2425 \\
\hline $\begin{array}{l}\text { Average time difference } \\
\text { (without starting difference) }\end{array}$ & & & \\
\hline
\end{tabular}




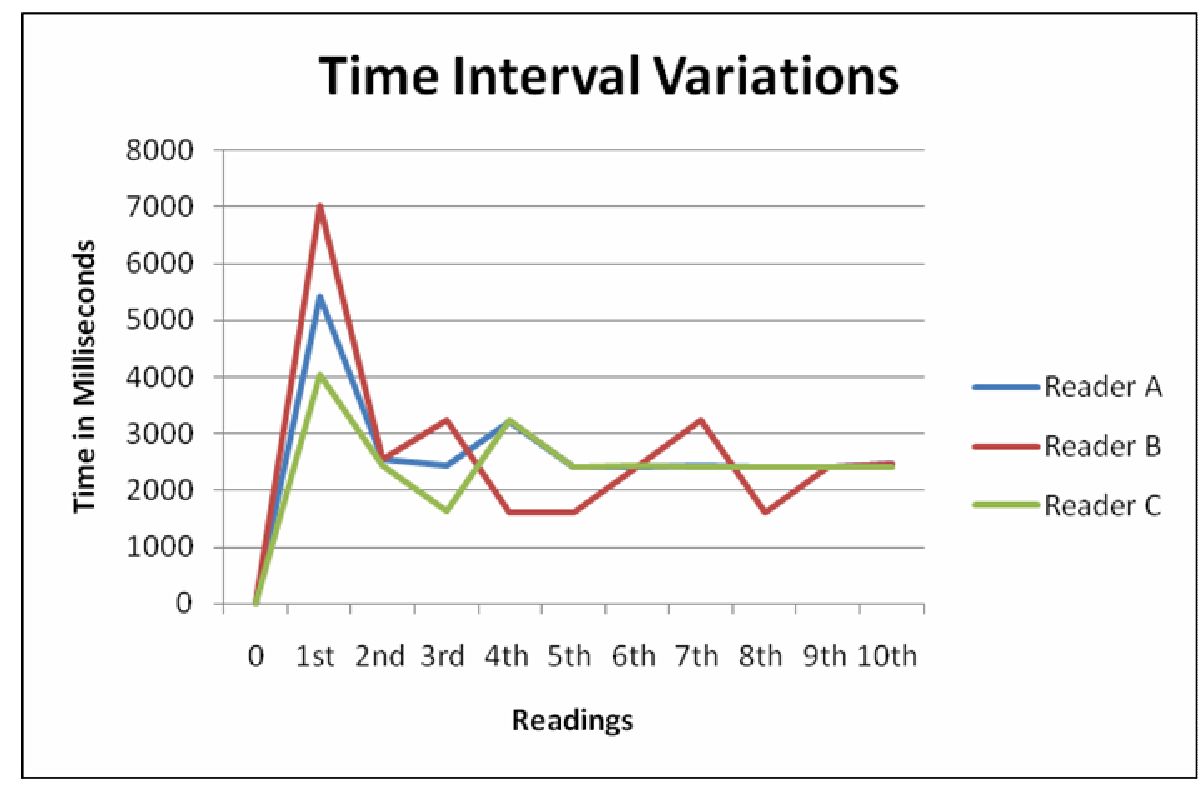

Figure 11. Time Interval Variations between readings

Data from the RFID readers are received in bursts at irregular intervals over the local area network. Table 1 shows the time difference data collected and has been used to generate the graph in figure 11 from which it can be seen that the first burst of data usually takes the longest time to reach the server while the subsequent bursts are less than 4000 milliseconds apart. From the data gathered we have also noticed that frequently the first burst contains no tag data at all and should therefore be discarded. Subsequent bursts can also miss data from a few tags. But in $90 \%$ of cases, 3 consecutive bursts of data ensure that all tags within the detection range are detected. Thus at most 20000 milliseconds $\left(\left(3^{*} 4000\right)+8000\right)$, are required for gathering sufficient tags' data for zone classification.

\subsection{The software application}

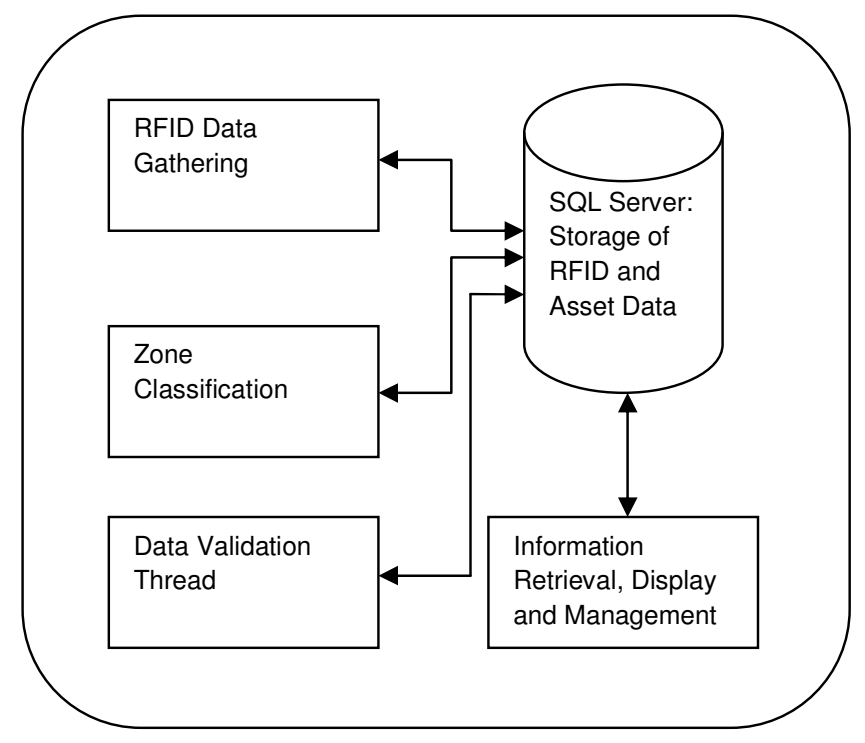

Figure 12. Main modules of the software application 
We have implemented the OZP application through four main modules as shown in figure 12. The 'RFID Data Gathering' module acts as a server, listening for data bursts sent to it by RFID Readers over the local area network. The data is temporarily stored in database for classification.

The 'Zone Classification' module is triggered every time sufficient data has been gathered or a time limit has been reached, that is, the end of a data gathering cycle. A simple algorithm classifies the RFID tags into their respective zones based on the combinations of readers that have been able to detect a tag during a data gathering cycle. The current zone for each tag is then updated in database.

Running in parallel, the 'Data Validation Thread' ensures that the current zone for each tag is still valid. That is, if during a detection cycle, not a single reader in the system has detected a particular tag, the latter's current zone needs to be updated to indicate that it has not been detected in any zone.

And the final module, the 'Information, Retrieval, Display and Management' module is responsible for feeding information to the user interface for display and allowing users to interact with the data collected.

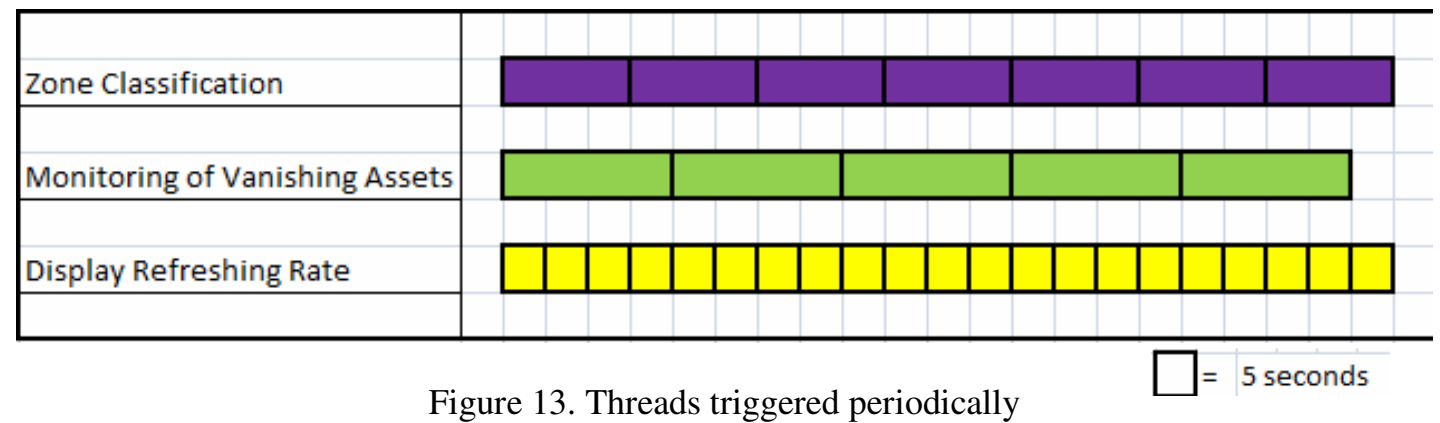

Figure 13 Shows the main threads which run periodically in parallel. The 'Zone Classification' thread is triggered every 15 seconds while the 'Monitoring of Vanishing Asset' from the Data Validation thread runs every 20 seconds. And the refreshing rate for the display is 5 seconds.

\section{RESUlTS \& DiSCUSSION}

After deployment of the system, we have tested it to validate our expectations. The test area is a corridor inside the Computer Science Department building at the University of Mauritius and is 50 metres long and 2.4 metres wide. We have deployed the readers as described earlier and used ten RFID active tags.

We tested two aspects simultaneously. These are:

(i) Cases where RFID Tags are within the boundary of a specific zone

(ii) Cases where RFID Tags are at varying distances outside the normal coverage area of the zone in (i).

Table 2, below, contains the data collected on the percentage of tags that have been correctly classified. A 2-period moving average was then performed in order to identify the trend. 
Table 2. Percentage and Moving Average of Correct Zone Classification

\begin{tabular}{|l|c|c|c|c|c|c|c|c|c|c|c|}
\hline $\begin{array}{l}\text { Reading } \\
\text { Number }\end{array}$ & 1st & 2nd & 3rd & 4th & 5th & 6th & 7th & 8th & 9th & 10th & $\begin{array}{l}\text { Average } \\
\text { Percentage }\end{array}$ \\
\hline $\begin{array}{l}\text { Percentage of } \\
\text { Correct Zone } \\
\text { Classification }\end{array}$ & 80 & 70 & 70 & 90 & 80 & 80 & 90 & 70 & 90 & 70 & 79.0 \\
\hline $\begin{array}{l}\text { 2 Periods } \\
\text { Moving } \\
\text { Average }\end{array}$ & & & & & & & & & & & \\
\hline
\end{tabular}

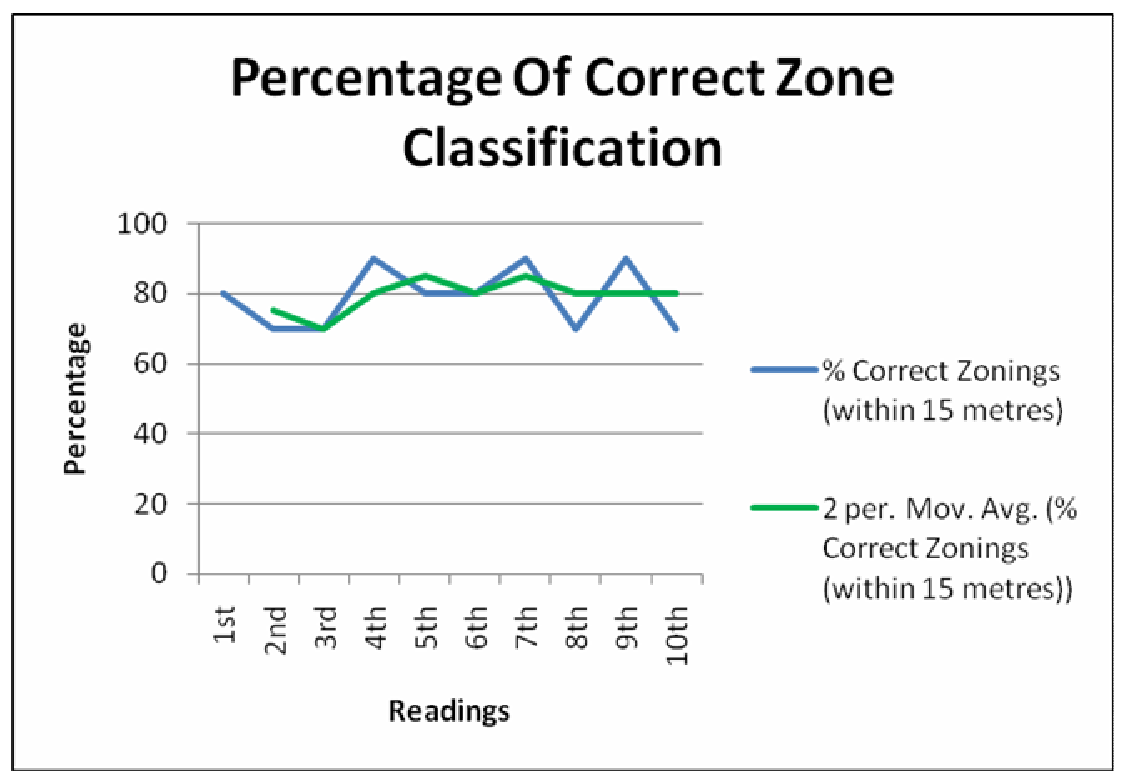

Figure 14. Percentage of Correct Zone Classification

From the graph in figure 14, we see that the OZP system has correctly identified the zone in which the RFID Tags were located in $79 \%$ of cases on average. Based from the data gathered, we have found that the upper accuracy limit has unfortunately not exceeded $90 \%$ while the lowest accuracy scored was $70 \%$. The moving average shows that in most cases, the accuracy level was maintained between $80 \%$ and $90 \%$.

Table 3. Percentage of False Positive Zone Classification

\begin{tabular}{|l|r|l|l|r|r|r|r|r|r|r|r|}
\hline Reading Number & 1st & $\begin{array}{l}\text { 2n } \\
\mathbf{d}\end{array}$ & 3rd & 4th & 5th & 6th & 7th & 8th & 9th & 10th & $\begin{array}{l}\text { Average } \\
\text { Percenta } \\
\text { ge }\end{array}$ \\
\hline $\begin{array}{l}\text { False Positives } \\
\text { (15m>Distance }<=20 m\end{array}$ & 30 & 40 & 20 & 30 & 40 & 20 & 40 & 40 & 30 & 40 & 33.0 \\
\hline $\begin{array}{l}\text { False Positives } \\
\text { (20m>Distance }<=25 m\end{array}$ & 20 & 10 & 20 & 20 & 10 & 0 & 10 & 10 & 20 & 20 & 14.0 \\
\hline $\begin{array}{l}\text { False Positives } \\
(\mathbf{2 5 m}>\text { Distance<=30m } \\
\text { (2) }\end{array}$ & 0 & 0 & 0 & 0 & 0 & 10 & 0 & 0 & 10 & 0 & \\
\hline
\end{tabular}




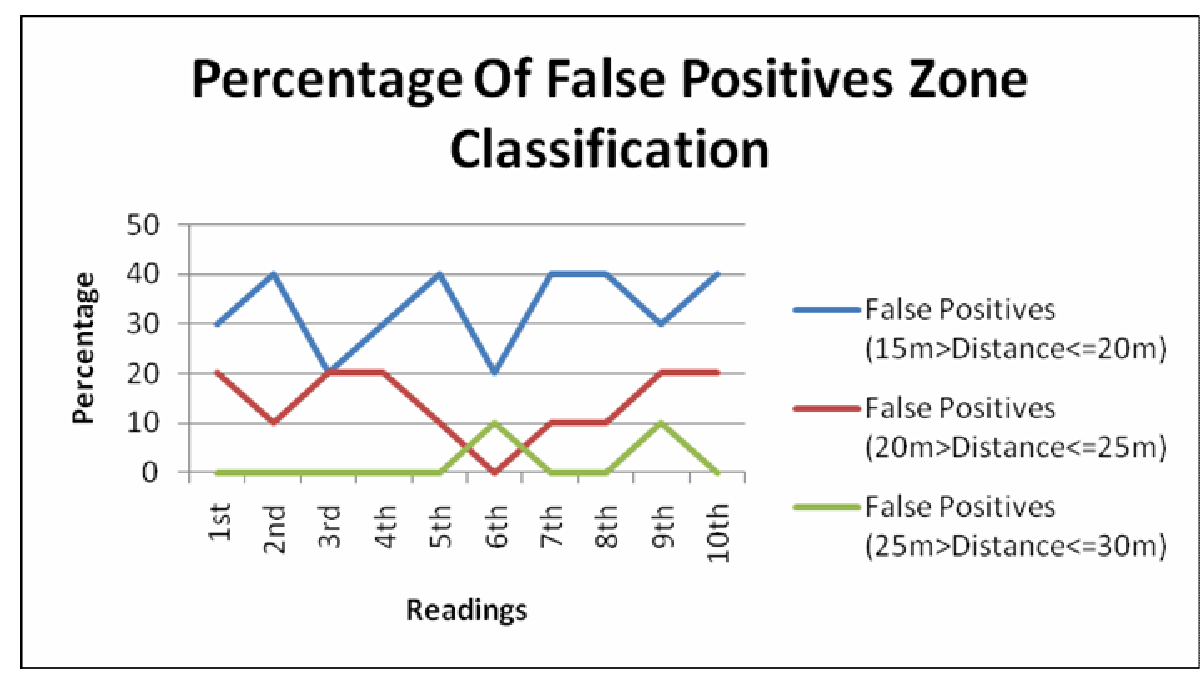

Figure 15. Percentage of False Positives Zone Classification

Since radio signals have no concrete boundary as such, we expected to have some false-positive zone classifications. These occur when RFID Tags theoretically beyond the coverage area of a reader is detected by the latter. These are caused mainly by reflection and multipath effects of the radio signals.

Within a distance on $5 \mathrm{~m}$ from the $15 \mathrm{~m}$ coverage area-radius, we have obtained a $33 \%$ false-positive classifications on average. But this has significantly dropped to $14 \%$ and $2 \%$ when moving further away (a distance 10m and 15 metres respectively for RFID Reader) as shown in figure 15.

We have observed that the correct classification and false positive cases were being affected by a number of factors. These are:

- The positioning of the RFID Readers and Tags

Readers placed at a higher distance from the floor tended to have a longer reading range than when placed directly on the floor. However, at ceiling's height, the range was almost similar to that at the floor's level. In order to maintain uniformity during testing, we placed all readers at a 50-metres height. The orientation of the RFID tags also played a role in the probability of them being detected. This becomes more important at distances beyond 10 metres. Tags laid flat were less likely to be detected than those whose flat surface was perpendicular to the floor.

- Presence of people in the test area

While the radio signals could travel through obstacles including humans, the coverage area was reduced with the presence of people in the test area. However, since most people were not stationary, the application successfully detected the tags within its normal coverage area.

- Opening and closing of doors along the test area

We noticed that in cases when doors were kept open along the test area, the coverage area tended to decrease. This was probably due to the fact that the signals were being reflected by the walls and doors all along the test area to cover longer distances which could be hampered when doors were kept open.

A comparison between OZP and a normal zone-based localisation system has been carried out. With the same number of RFID readers and same test area, we have obtained the following location accuracy:

OZP: $10 \mathrm{~m} * 2.4 \mathrm{~m}=24$ Metre Square \& Normal Zone-Based: $16.7 \mathrm{~m} * 2.4 \mathrm{~m}=40$ Metre Square. 
where $2.4 \mathrm{~m}$ is the width of the test area, $10 \mathrm{~m}$ is the diameter of a zone (out of five) in OZP while $16.7 \mathrm{~m}$ is the diameter of a zone in a normal Zone-Based system having three zones. We find that the accuracy has been enhanced as shown by a reduced location area by $40 \%(((40-24) / 40) * 100)$.

\section{CONCLUSIONS \& FUTURE WORK}

OZP has been demonstrated as an easily deployable system, capable of using basic off-the-shelf RFID readers and with minimal investment in terms of financial cost and implementation time.

Based on test results, we have found that OZP can perform classification with an accuracy of up to $90 \%$ even in cases where there are obstacles such as doors or even people in the coverage area. In comparison to a normal zone-based system, OZP yields locations $40 \%$ more accurately.

However, more testing is required to determine its suitability in areas separated by concrete walls. Future works will revolve around adapting OZP for such cases as well as enhancing its accuracy by programmatically varying coverage radius of each reader to create more zones but smaller in area.

\section{REFERENCES}

[1] Rieback, M. R., Crispo, B., Tanenbaum, A. S.,(2006). "The Evolution of RFID Security," IEEE Pervasive Computing, pp. 62-69, January-March, 2006

[2] Wants, R., (2006), “An Introduction to RFID Technology”, IEEE Pervasive Computing, v.5 n.1, p.25, January 2006

[3] Roberts C.M. (2007). "Radio frequency identification (RFID)." Computers and Security, 25 (1), pp. $18-26$.

[4] Rutner, S., Waller, M., Mentzer, J. (2004). “A practical look at RFID.” Supply Chain Management Review, Vol. 8 No.1, pp.36-41.

[5] RFID Gazette (2004). "The Future Is Here: A Beginner's Guide to RFID.” Retrieved November 25, 2009 from http://www.rfidgazette.org/2004/06/rfid_101.html

[6] Wang, S.,Chen, W.,Ong, C.,Liu, L., \& Chuang, Y.,(2006) . "RFID Application in Hospitals: A Case Study on a Demonstration RFID Project in a Taiwan Hospital." Proceedings of the 39th Annual Hawaii International Conference on System Sciences - Volume 08, IEEE Computer Society, 2006, p. 184.1.

[7] Irnich W., (2002). "Electronic security systems and active implantable medical devices." PACEPACING AND CLINICAL ELECTROPHYSIOLOGY (PACE), 25 (8), pp. 1235-1258.

[8] Anon, (2002). "Florida airport gets first RFID system" IIE SOLUTIONS 34 (7), pp.14-14., 2002.

[9] Sanpechuda, T. \& Kovavisaruch, L.,(2008). "A review of RFID localization: Applications and techniques." Electrical Engineering/Electronics, Computer, Telecommunications and Information Technology, 2008. ECTI-CON 2008. 5th International Conference, 2008, pp. 769-772.

[10] Priyantha, N.B., Chakraborty, A., and Balakrishnan, H.,.(2000). "The cricket location support system." In Mobile Computing and Networking, pages 32-43, 2000.

[11] Ward, A., Jones, A., and Hopper, A.(1997) . "A new location technique for the active office."In IEEE Personnel Communications, 4(5), pages 42-47, Oct. 1997.

[12] Ladd, A., Bekris, K., Marceau, G., Rudys, A., Kavraki, L. and Wallach, D.(2002). "Roboticsbased location sensing using wireless ethernet." In Proceedings of the Tenth ACM International Conference on Mobile Computing and Networking (MOBICOM), 2002.

[13] Aalto, L., Gothlin,N., Korhonen, J., and Ojala, T.(2004). "Bluetooth and WAP push based locationaware mobile advertising system." In MobiSYS '04: Proceedings of the 2nd international conference on Mobile systems, applications, and services, pages 49-58. ACM Press, 2004.

[14] Otsason, V., Varshavsky, A., LaMarca, A. and De Lara, E.,(2005). “Accurate GSM Indoor Localization." UbiComp 2005: Ubiquitous Computing, 2005, pp. 141-158. 
[15] Khedo, K., Sathan, D., Elaheebocus, R., Subramanian, R., Rughooputh, S.,(2010). "Development of Zone-based and Time-based Localisation Techniques for the RFID Technology", University of Mauritius, 3rd Research Week 2009-2010, International Conference, 15-19 February 2010.

[16] Assad, M.A.,(2007).”A real-time laboratory testbed for evaluation localization performance of WIFI RFID technologies.” MSc Thesis, Worcester Polytechnic Institude, May 2007

[17] Kanaan, M., Heidari, M., Akgul, F.O. \& Pahlavan, K., (2006). "Technical aspects of localization in indoor wireless networks." Bechtel Telecommunications Technical Journal, 2006

[18] Medidi, M., Slaaen, R. A., \& Zhou, Y. (2006). "Cluster-based localization in wireless sensor networks." Proceedings of the Society for Photo-Instrumentation Engineers, 6248(May), 62480J. doi:10. 1117/12.672880.

[19] Moore, D., Leonard, J., Rus, D., \& Teller, S. (2004). "Robust distributed network localizationwith noisy range measurements." In Proceedings of the 2nd International Conference on EmbeddedNetworked Sensor Systems, November 2004, pp. 50-61.

[20] Payne, K., Everist, J., Hou, F., \& Shen, W. (2006). "Single-sensor probabilistic localization on the SeReS self-reconfigurable robot." In Proceedings of the 9th International Conference on Intelligent Autonomous Systems, March 2006, pp. 207-216.

[21] Klee, U., Gehrig, T., \& McDonough, J. (2006). "Kalman filters for time delay of arrival-based source localization." EURASIP Journal on Applied Signal Processing, 2006, 1-15. doi:10.1155/ASP/2006/ 12378 .

[22] Chen, W., Li, W., Shou, H., Yuan, B., \& Wei, L. (2007). "Research on node localization based on Kalman filter for WSNs.” Journal of Wuhan University of Technology, 29(8), 112-116

[23] Kwon, T., Yang, J., Song, J., \& Chung,W. (2006). "Efficiency improvement in Monte Carlo localization through topological information." In Proceedings of the IEEE/RSJ International Conference on Intelligent Robots and Systems, October 2006, pp. 424-429.

[24] Ni, L.M., Liu, Y., Lau, Y.C. \& Patil, A.P., (2003). "LANDMARC: Indoor Location Sensing Using Active RFID.” IEEE Int. Conf. Pervasive Computing and Communication, pp. 407-415, March 2003.

[25] Kanaan, M. and Pahlavan, K., (2004). "CN-TOAG: A New Algorithm for Indoor Geolocation”. Proceedings of the 15th IEEE International Symposium on Personal, Indoor and Mobile Radio Communications, Vol. 3, pp. 1906-1910, PIMRC 2004, Barcelona, Spain,September 2004.

[26] He, T., Huang, C., Blum, B. M., Stankovic, J. A., \& Abdelzaher, T. F. (2005). "Range-free localization and its impact on large scale sensor networks." ACM Transactions on Embedded Computing System, 4(4), 877-906; TECS. doi:10.1145/1113830.1113837.

[27] Song, J.,Haas,C.H.,\&Caldas, C. H. (2007). “A proximity-based method for locating RFID tagged objects." Advanced Engineering Informatics, 21, 367-376. doi:10.1016/j.aei.2006.09.002.

[28] Zhou, J., \& Shi, J.,(2008) "RFID localization algorithms and applications-a review." Journal of Intelligent Manufacturing. July 2008

[29] Brunato,M.,\&Battiti, R. (2005). "Statistical learning theory for location fingerprinting in wireless LANs.” Computer Networks, 47, 825-845.doi:10.1016/j.comnet.2004.09.004.

[30] Nguyen, X., Jordan, M. I., \& Sinopoli, B. (2005). “A kernel-based learning approach to ad hoc sensor network localization.” ACM Transactionson Sensor Networks, 1(1), 134-152. doi:10.1145/1077391.1077397. 